\title{
Parental recall of birth weight: how accurate is it?
}

\author{
John J O’Sullivan, Mark S Pearce, Louise Parker
}

\begin{abstract}
Objective-To assess the accuracy of parental recall of birth weight in a British population and to investigate whether social class and age of the child significantly influence the accuracy of recalled birth weight.

Methods-A questionnaire was given to parents whose children were participating in a blood pressure study and the hospital records were retrieved to check the birth weight data.

Results-At the time of the study, the children $(n=649)$ ranged in age from 6 to 15 years. Seventy five per cent of the recalled birth weights were within $50 \mathrm{~g}$ of that recorded in the hospital records. No significant associations were found between the difference in birth weights (recalled birth weight minus hospital record) and social class of the parents or age of the child at time of data collection. Conclusion-This large study shows that parental recall of birth weight is good across the social classes and up to 16 years after delivery. There was no evidence of systematic bias, which would prejudice results of studies on the relation of birth weight to adult hypertension.

(Arch Dis Child 2000;82:202-203)
\end{abstract}

Keywords: birth weight; parental recall

Over the past 10 years there has been considerable interest in the association between factors in early life; in particular, size and shape at birth and subsequent risk of ischaemic heart disease, obesity, hypertension, and glucose intolerance. ${ }^{12}$ A number of studies on the relation between birth weight and adult blood pressure have resulted. Because of the absence of contemporary records, a number of studies in children obtained birth weight data using parental recall. ${ }^{3-8}$ The purpose of our study was to test the accuracy of parental recall of birth weight for children of different ages.

Table 1 Accuracy of recalled birth weight when compared with that recorded in the hospital notes

\begin{tabular}{ll}
\hline Recalled versus hospital weight & Number (\%) \\
\hline Within $10 \mathrm{~g}$ & $298(46)$ \\
Within $50 \mathrm{~g}$ & $494(76)$ \\
Within $100 \mathrm{~g}$ & $550(85)$ \\
Within $200 \mathrm{~g}$ & $589(91)$ \\
Within $225 \mathrm{~g}$ & $597(92)$ \\
Within $300 \mathrm{~g}$ & $612(94)$ \\
Within $500 \mathrm{~g}$ & $628(97)$ \\
Within $1000 \mathrm{~g}$ & $647(99.7)$ \\
Within $1500 \mathrm{~g}$ & $649(100)$ \\
\hline
\end{tabular}

\section{Methods}

During the 1995-96 school year, a large study measuring the blood pressure of school children was carried out in Newcastle upon Tyne. As part of the study, parents were asked to complete a questionnaire, which included a request for information on the child's birth weight, the accuracy of which it was considered necessary to validate. The questionnaire did not specify which parent completed it. The hospital birth records were retrieved and birth weight, gestation, father's occupation, and planned method of feeding were noted. Social class was assigned on the basis of father's occupation. ${ }^{9}$ The birth weights were virtually always given in ounces and were converted to grams for analysis. As the difference between recalled birth and recorded birth weight was not normally distributed ( $p<0.0001)$, standard non-parametric Kruskal-Wallis tests were used to test the influence of different factors on the accuracy of parental recall of birth weight.

\section{Results}

The study comprised 649 children (372 girls) born in Newcastle upon Tyne between 17 March 1980 and 9 August 1989 in two hospitals. The birth weight as recorded in the hospital records ranged from $1700 \mathrm{~g}$ to $4995 \mathrm{~g}$ (mean, 3380), and there was some evidence that the figures had been rounded off to 0 and 5. The difference between recalled birth weight and recorded birth weight ranged from $-1190 \mathrm{~g}$ to $+1390 \mathrm{~g}$ (mean, -11 ; median, -6 ).

Recalled and recorded birth weights were highly correlated $(r=0.95)$ and the differences were not significant $(\mathrm{p}=0.71)$. Table 1 shows that over $90 \%$ of recalled birth weights were within $200 \mathrm{~g}$ of that recorded. No significant associations were observed between the difference in birth weights and social class $(\mathrm{p}=0.65)$, sex $(\mathrm{p}=0.87)$, hospital $(\mathrm{p}=0.32)$, age of child at time of interview $(p=0.49)$, or planned feeding method $(p=0.39)$. Table 2 divides the recorded birth weight into various groups, and the recalled birth weight at either extreme was not significantly better than the middle group. Accuracy of recalled birth weight did not vary according to the recorded birth weight $(\mathrm{p}=0.44)$.

Table 2 Median difference and range (of recalled minus recorded birth weight) according to recorded birth weight and age of child

\begin{tabular}{lccl}
\hline & $n$ & Median difference & Range \\
\hline \multicolumn{2}{l}{ Recorded birth weight $(\mathrm{g})$} & & \\
$\quad 32500$ & 36 & -7.5 & -220 to 970 \\
$2501-4000$ & 544 & -10 & -770 to 1390 \\
$>4000$ & 69 & 0 & -460 to 580 \\
Age of child (years) & & & -1190 to 1390 \\
$6-9$ & 272 & -5 & -815 to 760 \\
$10-12$ & 163 & -5 & -770 to 970 \\
$13-15$ & 214 & -10 & \\
\hline
\end{tabular}


Discussion

Obtaining hospital birth records to verify birth weight can be tedious, particularly if the individual was born a number of years ago or in another part of the country. When asked, parents are usually quick to remember their child's birth weight. This is not surprising because this piece of information is usually eagerly awaited at the time of delivery and also repeatedly relayed to friends and family, thereby imprinting it to memory. However, time can blur the details, ${ }^{10}{ }^{11}$ and the figure may be "rounded off" 12 or confused with other deliveries.

A number of studies on birth weight ${ }^{3-8}$ have used maternal recall as the basis of their data and it is obviously important that the validity of this is checked. An Irish study ${ }^{13}$ of 99 mothers concluded that recall accuracy was better for the higher social classes and became worse as the child's age increased. A systematic error in birth weight recall where the error is greater for lower social class could introduce significant bias into studies of risk factors for ischaemic heart disease, where social class is in itself an important risk factor. Three UK studies ${ }^{14-16}$ found that the accuracy of recalled birth weight was good, but that even a few months after delivery there was a tendency for mothers to report slightly higher birth weights. ${ }^{14}$

Analysis of data from the USA diethylstilbestrol study ${ }^{17}$ found good to excellent recall of birth weight, but there was a significant difference in accuracy between the study parents and the mothers of a control group. The reasons for this difference between groups were not explored. ${ }^{17} \mathrm{~A}$ study from Israel of 97 women, who had at least seven children each, found that about $75 \%$ of reported weights were accurate to within $100 \mathrm{~g} .{ }^{18}$ Recall was best when children were less than 4 years old but was not related to maternal age or education. A Swedish study of laboratory workers found that after about 7 years, recalled birth weight was within $50 \mathrm{~g}$ of the recorded weight in $87 \%$ of the study population. ${ }^{19}$ However, these results of studies of specific ethnic ${ }^{18}$ and occupational groups ${ }^{19}$ might not be applicable to the general population, and further studies were needed.

We found in a relatively large study, representing all social classes, that parental recall was good, with $75 \%$ of recalled birth weights being within $50 \mathrm{~g}$ of that recorded in the hospital records. We found that recall was not different for different social classes and was good for children born up to 15 years previously. Other studies have found more inaccuracy at the extremes of weight, ${ }^{12}{ }^{17}$ but this was not evident in our study. In general, it appears that recalled birth weights are sufficiently accurate for use in epidemiological investigations. In particular, because our study found no association with social class or the age of the child, any error will be random and therefore not likely to introduce systematic bias.

1 Barker DJP, Osmond C, Golding J, Kuh D, Wadsworth MEJ. Growth in utero, blood pressure in childhood and adult life, and mortality from cardiovascular disease. $B M 7$ 1989;298:564-7.

2 Barker DJP. Early growth and cardiovascular disease. Arch Dis Child 1999;80:305-10.

3 Whincup P, Cook D, Papacosta O, Walker M. Birth weight and blood pressure: cross sectional and longitudinal relations in childhood. BMF 1995;311:773-76.

4 Whincup PH, Cook DG, Papacosta O. Do maternal and intrauterine factors influence blood pressure in childhood? Arch Dis Child 1992;67:1423-9.

5 Taittonen L, Nuutinen M, Turtinen J, Uhari M. Prenatal and postnatal factors in predicting later blood pressure among children: cardiovascular risk in young Finns. Pediatr Res 1996;40:627-32.

6 Walker BR, McConnachie A, Noon JP, Webb DJ, Watt GCM. Contribution of parental blood pressures to association between low birth weight and adult high blood pressure: a cross sectional study. BMF 1998;316:834-7.

7 Taylor SJC, Whincup PH, Cook DG, Papacosta O, Walker M. Size at birth and blood pressure: cross sectional study in 8-11 year old children. BMF 1997;314:475-80.

8 Uiterwaal CSPM, Anthony S, Launer LJ, et al. Birth weight, growth, and blood pressure. An annual follow-up study of children aged 4 through to 21 years. Hypertension 1997;30: 267-71.

9 Office of Population Censuses and Surveys (OPCS). Standard occupation classification, Vols 1, 2, 3. London: HMSO, 1990.

10 Haggard EA, Brekstad A, Skard AG. On the reliability of the namnestic interview. Fournal of Abnormal and Social Psychology 1960;61:311-18.

11 Ley P. Primacy, rated importance and the recall of medical statements. F Health Soc Behav 1972;13:311-19.

12 Axelson G, Rylander R. Validation questionnaire reported miscarriage, malformation and birth weight. Int $\mathcal{F}$ Epidemiol 1984;13:94-8.

13 Sheehan P, MacAirt J. Reliability of mothers' recall of birth data. Ir Med f 1981;74:75

14 Cartwright A, Smith C. Some comparisons of date from medical records and from interviews with women who had recently had a live birth or stillbirth. F Biosoc Sci 1979;11:49-64.

15 Joffe M, Grisso JA. Comparison of antenatal hospital records with retrospective interviewing. 7 Biosoc Sci 1985;17:113-17.

16 Whincup PH, Cook DG, Adshead F, et al. Cardiovascular risk factors in British children from towns with widely differing adult cardiovascular mortality. BMF 1996,313:7984

17 Tilley BC, Barnes AB, Bergstralh E, et al. Comparison of pregnancy history recall and medical records. Am $\mathcal{F}$ Epidemiol 1985;121:269-81.

18 Seidman DS, Slater PE, Ever-Hadani P, Gale R. Accuracy of mother's recall of birth weight and gestational age. $\mathrm{Br} \mathcal{F}$ Obstet Gynaecol 1987;94:731-5.

19 Robbins LC. The accuracy of parental recall of aspects of child development and of child rearing practices. Fournal of Abnormal and Social Psychology 1963;66:261-70. 